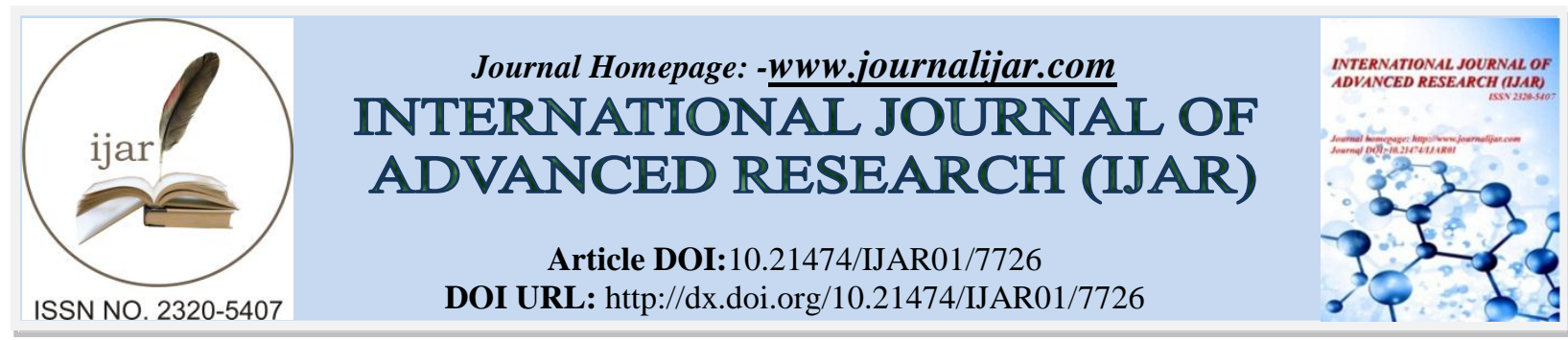

RESEARCH ARTICLE

\title{
A CLINICAL STUDY ON MANAGEMENT OF SLOW FLOW VASCULAR MALFORMATION WITH FOAM SCLEROTHERAPY.
}

\section{Dr.Prabhakaran M,Prof.Dr.Jayachander K,Prof.Dr.Elancheralathan K,Dr.Shanmugavelayutham C and Dr.Deepankumar B.}

\section{Manuscript Info}

Manuscript History

Received: 21 July 2018

Final Accepted: 27 August 2018

Published: September 2018

Keywords:-

slow flow vascular malformation,foam sclerotherapy.

\section{Abstract}

Aim of Study:The objective of this study is the management of symptomatic slow-flow vascular malformations with foam sclerotherapy.

Materials and Methods:Out of 35 patients with vascular malformation intervened ,17 (50\%)patients with symptomatic slow flow vascular malformation were prospectively evaluated and subjected to foam sclerotherapy under fluoroscopy and ultrasound guidance.

Results: A total of 17 patients were included in the study.Of which $12(71 \%)$ were female and 5(29\%) were male.82\% (14)of patients presented with pain.Among patient who presented with pain $78 \%(11)$ had 95\% improvement in pain with single session.Out of the $17,30 \%(5)$ of patients with previous history of surgery required more number of session for symptom(pain) reduction when compared to patients presented with primary lesion.

Conclusion:Foam sclerotherapy can be used successfully to treat slow flow vascular malformation with less complications.In pediatric patients presenting with diffuse lesions,sclerotherapy is the initial viable modality and surgical intervention can be postponed.

Copy Right, IJAR, 2018,. All rights reserved.

\section{Introduction:-}

Venous malformations (VMs) are the commonest type of vascular malformations, with varied presentations including disfigurement, pain, swelling, etc. Percutaneous injection sclerotherapy has evolved as an effective treatment option for slow-flow malformations. Various agents and techniques are described in literature with varying results.

\section{Methodology:-}

Patients presented one or more symptomatic vascular malformations, uniquely or predominantly venous including those combined with lymphatic malformations treated by foam ultrasound-guided sclerosis at the Department of Vascular surgery from 2015to 2018. A history of previous treatment (embolisation, sclerotherapy or surgery) was not an exclusion criterion. There was no age limit for inclusion. The indication for ultrasound-guided sclerosis was rejected in cases of asymptomatic lesions, the presence of associated arterial malformations, poor treatment compliance and the existence of a contraindication to ultrasound-guided sclerosis (such as a history of thromboembolic disease or known patent foramen ovale). The pre-therapeutic evaluation was primarily clinical to clarify the 
symptoms (pain, neurological signs and trophic disorder) and the type and size of the malformation(s). Photographs were taken. Duplex ultrasonography was routinely performed, often supplemented with an angio-magnetic resonance imaging (MRI). Clear information about the ultrasound-guided sclerosis treatment was given to the patient both orally and in writing.

\section{Results and Discussion:-}

\section{Procedure}

The treatment was performed in an operating room. The patient's written consent, or that of the parents of a juvenile patient, was obtained. At the beginning of each treatment session, a pretreatment doppler was carried out to verify the type, depth and accessibility of the malformation.

The sclerosing agent used was sodium tetradecylsulphate at concentrations ranging from $0.25 \%$ to $0.5 \%$, according to the site,size and depth of the lesion and the response to previous treatment. Foam was produced by Tessari's method, the sclerosing liquid being diluted with air at a ratio of 1 volume of liquid sclerosant to 4 volumes of air. Colour Doppler ultrasonography was performed. The patient was supine or prone, according to the topography of the lesion. First, a syringe or a short catheter $(20 \mathrm{G} / 22 \mathrm{G}$ butterfly) was inserted under ultrasound-guided control. Under fluoroscopy contrast injected to localize the lesion, look for any draining veins and to assess the amount of foam needed. The volume of foam injected was estimated by the amount necessary to obtain a venous spasm, but never exceeded $5 \mathrm{ml}$. Compression by superposing an Elastoplast tape was applied immediately after treatment and maintained for 1 day when the topography permitted. The patient was kept under surveillance for $2-3 \mathrm{~h}$ after the invasive procedure. After this, if the malformation was on a limb, an elastic compression stocking (20-36 mmHg) was worn during the day for 15 days.

A total of 17 patients were included in the study. Of which $12(71 \%)$ were female and $5(29 \%)$ were male. The most common age group presented was among 21 to 30 years which include $8(47 \%)$ patients.Followed by $4(23.5 \%)$ patients each in $<10$ years and 11 to 20 years age group. Age range is from 5 years to 42 years. Mean age was 19 years.

The most common presenting symptom was pain in $11(64 \%)$ of patients followed by swelling in $3(18 \%)$ of patients. The remaining $3(18 \%)$ had both pain and swelling as symptom.

Extremity was the most commonly involved site.In $8(47 \%)$ patients the lesion was in lower extremity,followed by $4(23.5 \%)$ patients involving upper extremity and head/neck each .Right lateral chest wall was involved in $1(6 \%)$ patient. Among the 17 patients 5(30\%) had previous surgery for the lesion in their childhood.

Each patient underwent MRI and ultrasound pre procedure for assessing the size and plane of the lesion aiding in post procedure comparison.In $8(47 \%)$ patients the lesion size was in range of $6-10 \mathrm{~cm}$. Of them $5(62 \%)$ had multiplane involvement. Calcifications and phlebolith were present in $6(35 \%)$ of patients. All the patient in the study had only venous component except one with lymphovenous component.

$82 \%(14)$ of patients presented with pain.Among these 35\%(5) were in pediatrics age group.Among patient who presented with pain $78 \%(11)$ had $95 \%$ improvement in pain with single session. Rest 22\%(3) patients required further sessions.About $50 \%$ reduction in size was observed in 14(80\%) of patients after an average of 3 sessions.3(20\%) patients who presented as recurrent lesion had $30 \%$ reduction in size. Lesions in the extremity responded well which may be attributed to the liberal use of the sclerosent when compared to lesion in face.Patient with previous surgical history required more number of session for symptom(pain) and size reduction when compared to patients presented with primary lesion which may be attributed to the damage of nerves resulted from surgery. Maximum number of sessions attempted were 6.Average number of sessions were 1.8 per person.The interval between sessions were 4 weeks period. There was no major complication except one patient had deep venous thrombosis and another patient had thrombophlebitis post sclerotherapy. The average followup period was 6 months. 


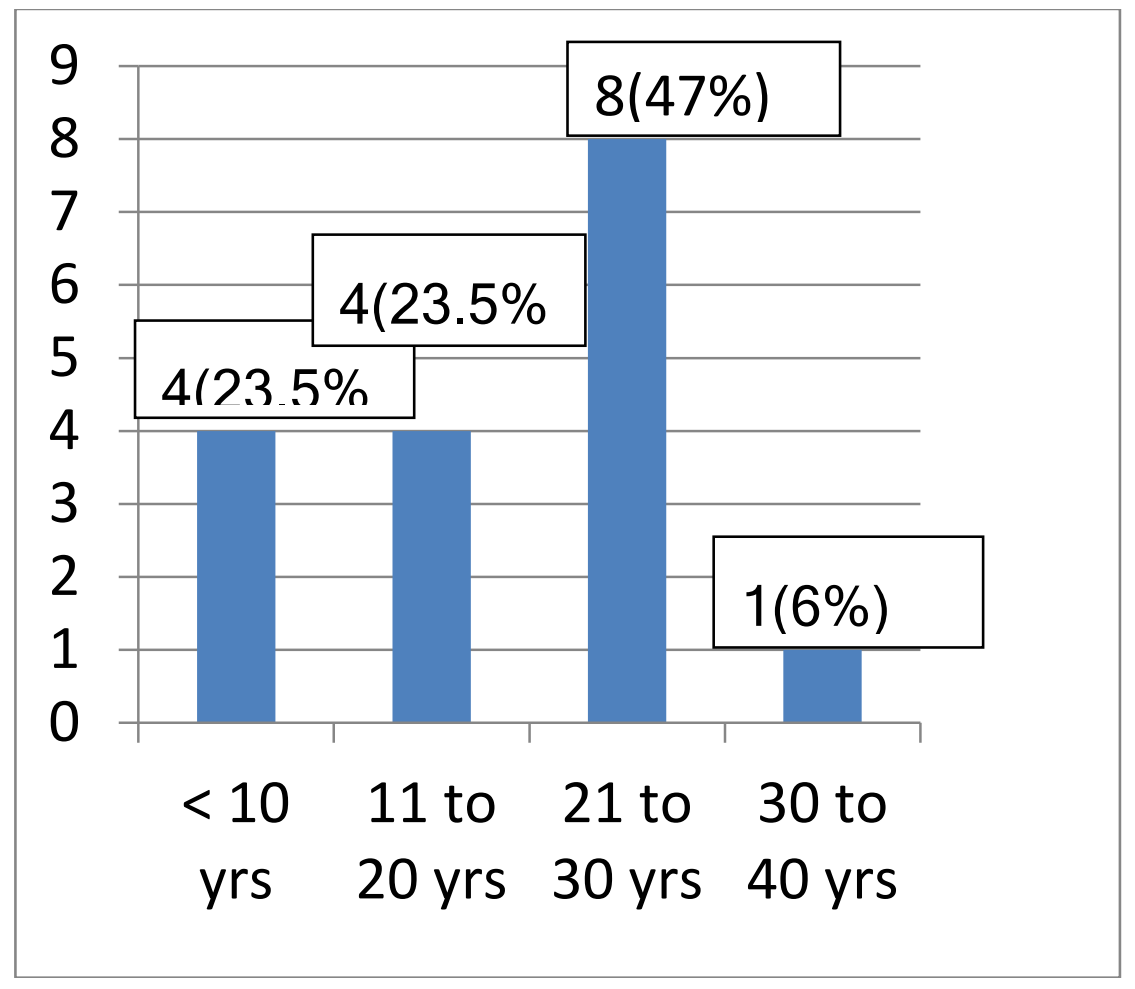

Fig 1:-incidence of age

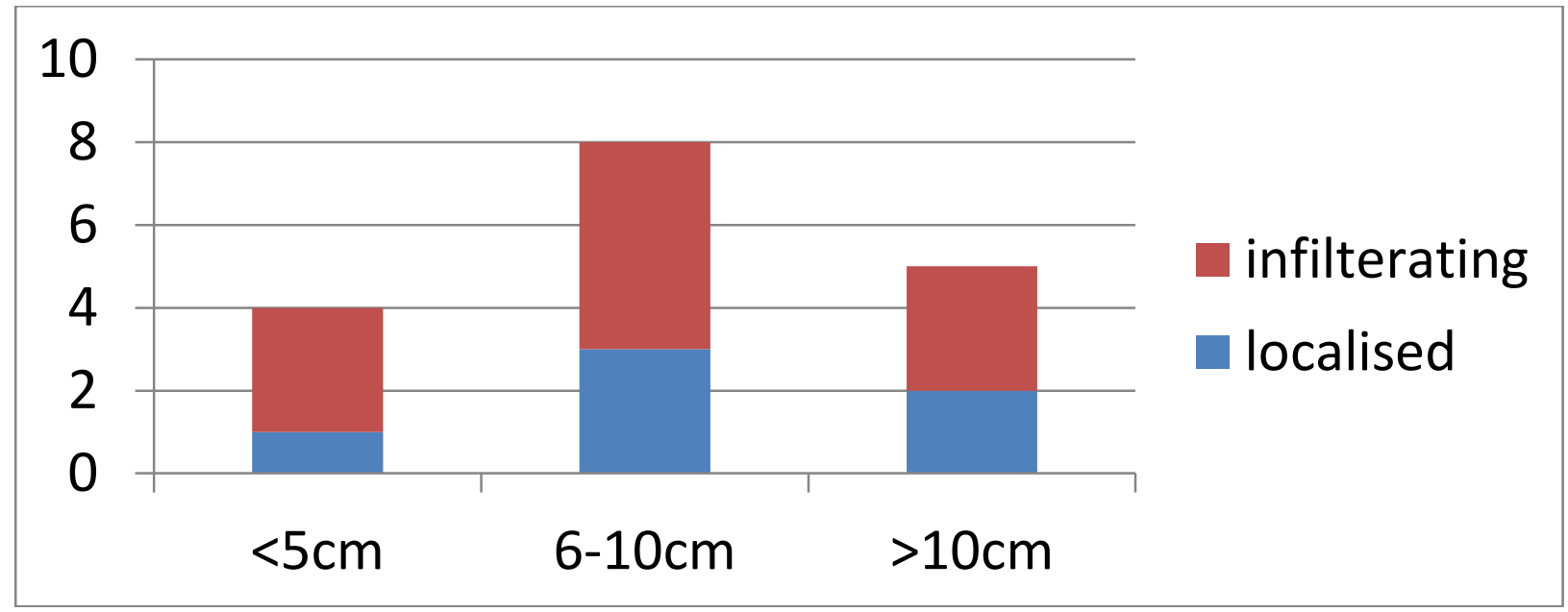

Fig 2:-size and type of lesion 


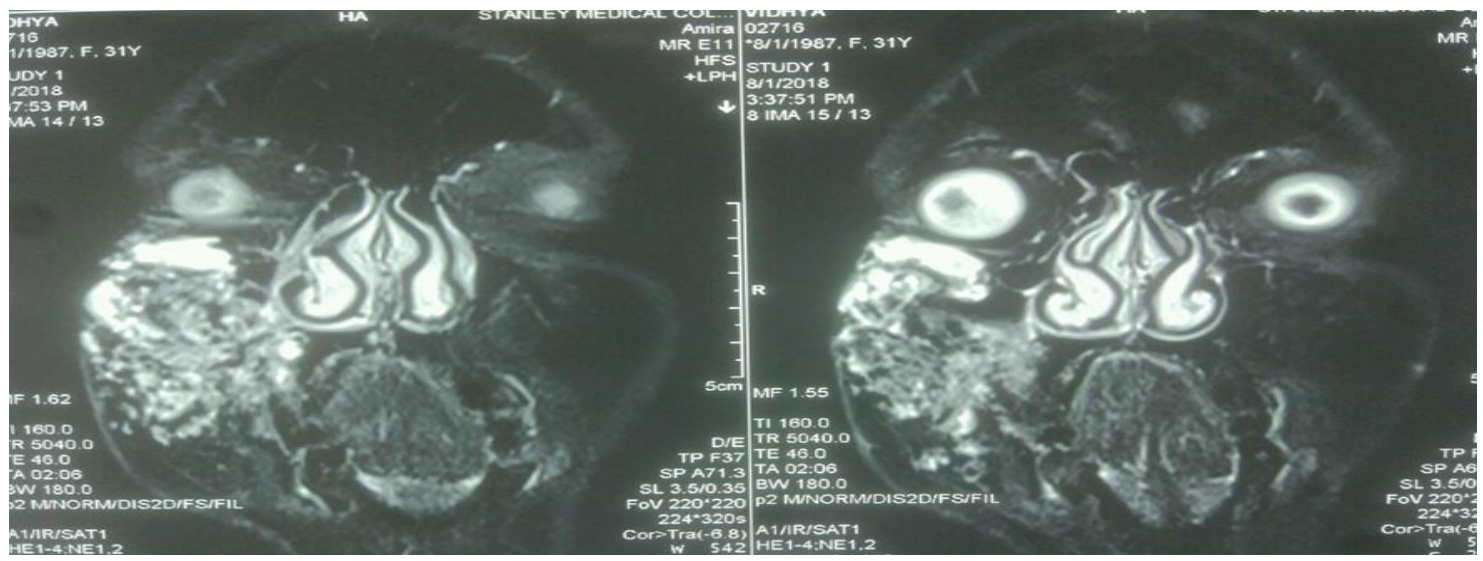

Fig 3:-MRI of a face venous malformation

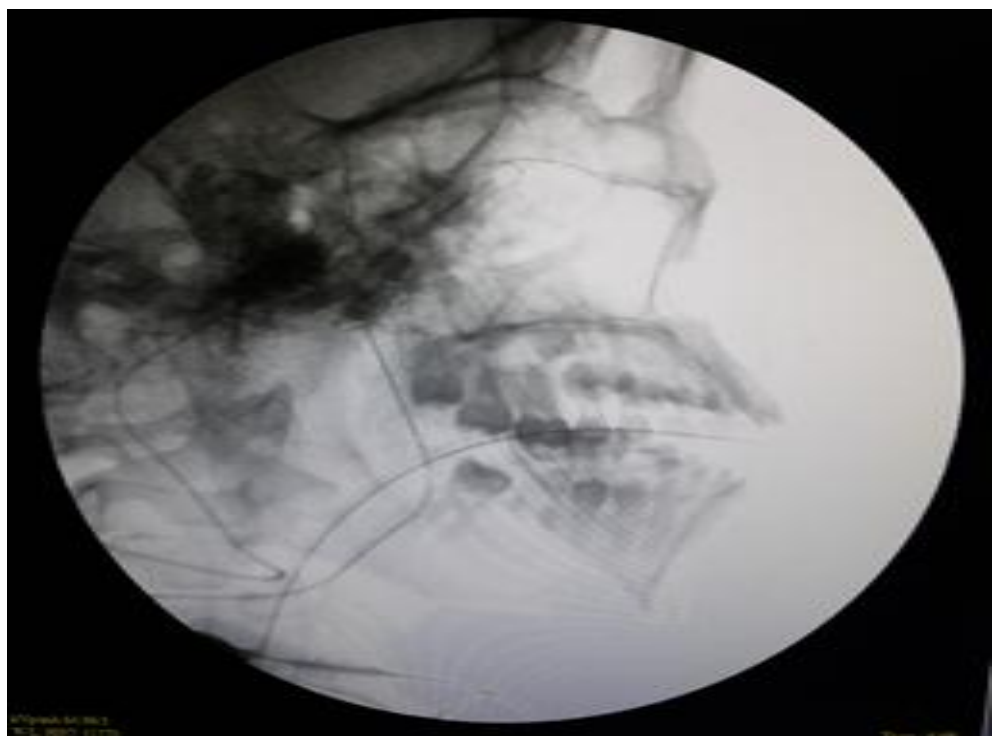

Fig 4:-arteriography

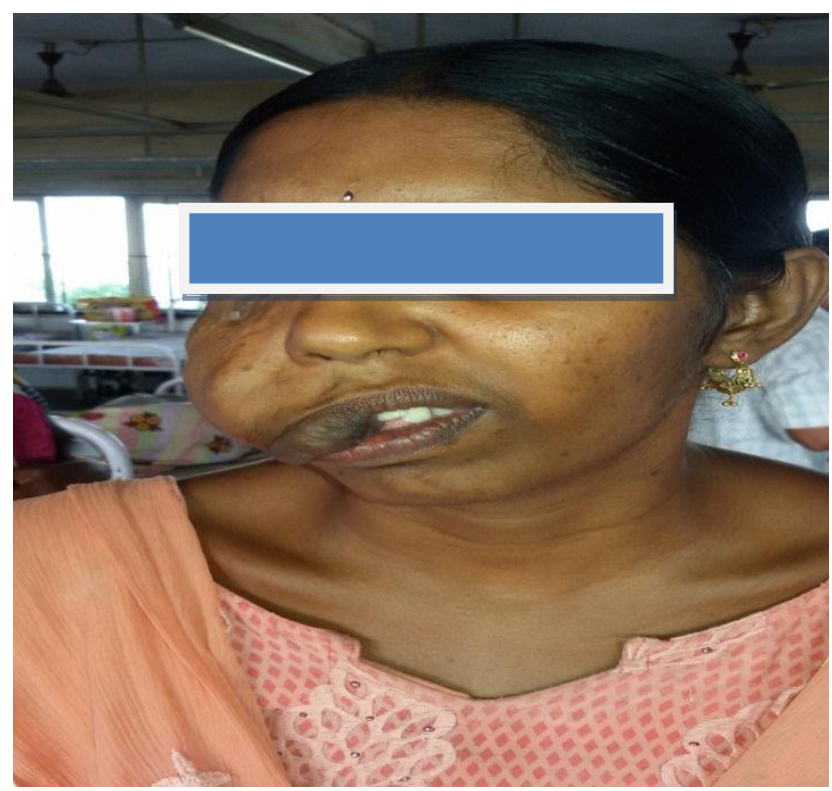

Fig 5:-before foam sclerotherapy 


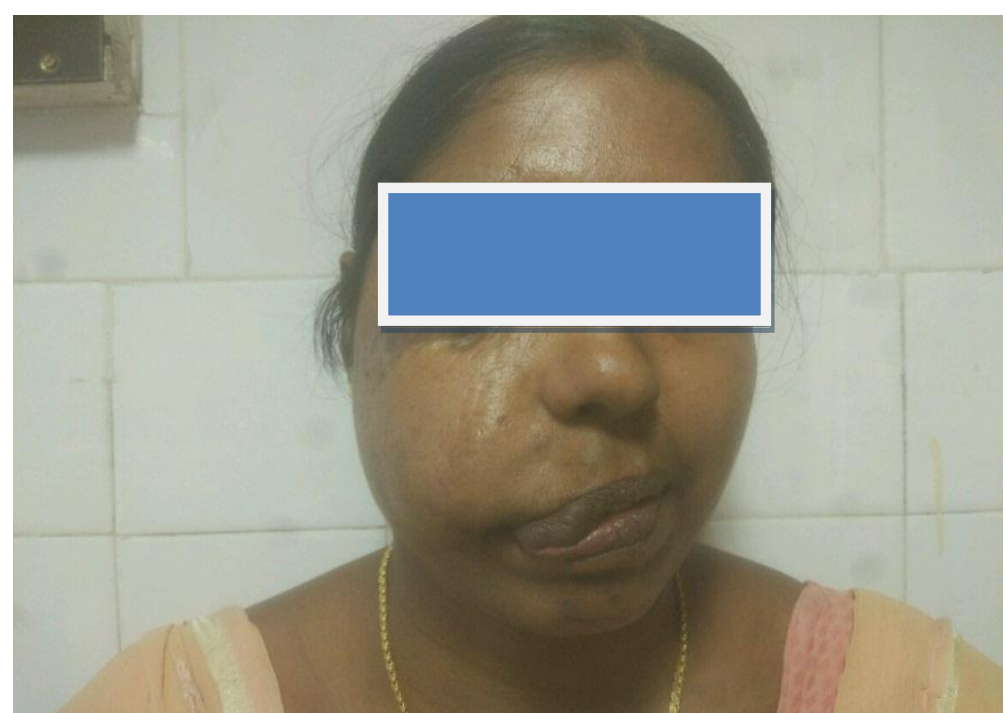

Fig 6:-after foam sclerotheraphy

\section{References:-}

1. SubhashKumar ,Ultrasound-guided polidocanol foam sclerotherapy for treating venous malformations,journal of clinical ultrasound,Volume46, January 2018

2. Balasundaram,The use of foam sclerotherapy to treat low-flow vascular malformations of the head and neck, J Surg Case Rep. 2014 Sep

3. Yamaki T, Nozaki M, Sakurai $\mathrm{H}$, et al. Prospective randomized efficacy of ultrasound guided foam sclerotherapy compared with ultrasound-guided liquid sclerotherapy in the treatment of symptomatic venous malformations. J Vasc Surg. 2008;47:578-584.

4. Yakes WF. Diagnosis and management of low-flow veno-lymphatic vascular malformations.CesRadiol. 2008;62:131-145.

5. Cabrera J, Cabrera J Jr, Garcia-Olmedo A, et al. Treatment of venous malformations with sclerosant in microform foam. Arch Dermatol. 2003;139:1409-1416. 